\title{
Perspectivas de crianças acolhidas institucionalmente sobre suas famílias de origem ${ }^{1}$
}

\author{
Fernanda Müller \\ Universidade de Brasília
}

\section{Resumo}

O estudo considerou como participantes seis crianças acolhidas institucionalmente em uma cidade da região metropolitana de São Paulo. Foram investigadas as perspectivas sobre a família de origem de crianças que mantêm vínculos com as mesmas. Uma abordagem de inspiração etnográfica foi utilizada em combinação com outros métodos, como fotografias e conversas subsequentes conduzidas com as crianças. A pesquisa mostra que crianças elaboram dinâmicas familiares alternativas, diferentes daquelas consideradas como padrão. As políticas sociais atuais nesta área têm falhado, sobretudo quando as famílias são consideradas culpadas pela situação de vulnerabilidade em que se encontram.

Palavras-chave: Dinâmicas familiares. Abrigo. Crianças em situação de risco. Políticas para a infância. 


\section{The views of children living in care concerning their families of origin}

This study considered as participants six children from public children's homes in a town in the metropolitan area of São Paulo, who still maintain contact with their family of origin, investigating their views of their families of origin. An ethnography inspired approach was used in conjunction with other methods, such as photographs and subsequent conversations with the children. The research demonstrates that children develop alternative family dynamics, different from those considered as standard. Current social policies in this area have failed, especially when families are considered guilty for the vulnerability situation in which they are.

Keywords: Familial dynamics. Children's homes. Vulnerable children. Childhood policies.

\section{Perspectivas de niños que viven en centros de acogida sobre sus familias de origen}

El estudio consideró como participantes seis niños de un centro de acogida de una ciudad en la región metropolitana de São Paulo. Investiga los puntos de vista acerca de las familias de origen de niños que mantienen vínculos. Se utilizó un enfoque etnográfico en combinación con otros métodos, como fotografías y conversaciones posteriores con los niños. Las investigaciones muestran que los niños elaboran dinámicas familiares alternativas que son diferentes de las consideradas estándar. Las políticas sociales actuales en esta área han fracasado, especialmente cuando las familias son consideradas las culpables de la situación de vulnerabilidad en que se encuentran.

Palabras clave: Dinámicas familiares. Centros de acogida. Niños en situación de riesgo. Políticas para la infancia. 


\section{Introdução}

0 Estatuto da Criança e do Adolescente (ECA), promulgado em 1990, em seu Art. 101, caracteriza o acolhimento institucional de crianças como "medida provisória e excepcional, utilizável como forma de transição para a colocação em família substituta, não implicando privação de liberdade". Tal medida pode ser tomada pelas Varas da Infância e Juventude ou pelos Conselhos Tutelares quando forem esgotadas todas as possibilidades de convivência familiar.

Sem dúvidas, o acolhimento institucional de crianças apresenta diferentes rupturas para elas e suas famílias. Daí a importância de dar visibilidade a estas famílias e recuperar as relações que as crianças mantêm com elas, a despeito de tudo, escutando o que as crianças têm a dizer. Pesquisas têm mostrado que a maioria das crianças abrigadas manifesta o desejo de voltar para as suas famílias de origem e raramente querem ser adotadas (Oliveira, 2007). Em programas de acolhimento familiar, Costa e Rossetti-Ferreira (2007) verificaram que mesmo quando crianças ficam sem ver a família por períodos longos, ao retornarem às suas casas, a maioria delas demonstra que os vínculos familiares permanecem, ainda que tenham sofrido violências.

0 "Levantamento Nacional de Abrigos para Crianças e Adolescentes da Rede SAC" (Ipea, 2003) identificou vinte mil crianças e adolescentes vivendo em 589 abrigos no país, sendo que $1 / 3$ das crianças e adolescentes abrigados encontravam-se no estado de São Paulo. Esta pesquisa mostrou que $86,7 \%$ das crianças e adolescentes abrigados possuem família, e dentre este universo, 58,2\% mantém vínculo com familiares (Ipea, 2003). Contudo, é importante ressaltar que o estudo do Ipea centrou-se somente nos abrigos cadastrados à Rede de Serviços de Ação Continuada (Rede SAC). De fato, atualmente, ainda não se sabe ao certo quantas crianças e adolescentes encontram-se abrigados no Brasil, mas estimase uma soma de mais de 80 mil, que não é precisa devido à falta de conexão entre diferentes bancos de dados.

Ainda que uma parcela significativa de crianças abrigadas possua família e com ela mantenha vínculo, pesquisas apontam que os abrigos possuem poucas informações sobre a família das crianças (Serrano, 2008). Além disso, Solon (2006) mostra que tampouco a Vara da Infância e Juventude possui os dados sobre as famílias quando as crianças são abrigadas em cidades diferentes daquela de origem. Todos esses elementos limitam a elaboração de políticas públicas de apoio às famílias e crianças abrigadas. Serrano (2008, p. 28) ainda argumenta que pouco se conhece sobre 0 acolhimento institucional de crianças, e, sobretudo, a falta de estatísticas e dados sistematizados dificulta a realização de ações mais efetivas. A condução de pesquisas em abrigos é, portanto, fundamental para entender as 
experiências das crianças privadas do convívio diário com suas famílias.

Delgado e Müller (2005) discutem que na área de educação muitos estudos são conduzidos em espaços educativos formais, sobretudo em escolas, e chamam atenção de que pouco tem sido produzido sobre espaços educativos não formais. Certamente os abrigos, como espaços institucionais de educação e cuidado às crianças, deveriam ser incorporados às agendas de pesquisa educacional: que práticas pedagógicas são conduzidas junto às crianças? Como elas se sentem em outros espaços, principalmente o escolar? Que relações o abrigo estabelece com a comunidade? Rossetti-Ferreira, Serrano e Almeida (2011) reuniram trabalhos que buscam responder a algumas destas questões.

0 presente estudo, por sua vez, interessa-se por uma questão pontual, mas que não foge igualmente das demandas de pesquisa da área educacional: quem faz parte do grupo familiar de crianças acolhidas institucionalmente e com quem estabelecem laços afetivos e de pertencimento? Posto isso, volta-se para a análise de diferentes dinâmicas familiares apresentadas por seis crianças acolhidas em três abrigos públicos², que mantêm vínculo com suas famílias. Também aborda um objeto de pesquisa ainda pouco explorado nas pesquisas acadêmicas, além de desconstruir a ideia negativa sobre dinâmicas familiares das camadas populares. A pesquisa, de inspiração etnográfica, foi conduzida em abrigos públicos de uma cidade da região metropolitana de São Paulo e contou com a participação direta das crianças.

É importante salientar que o trabalho se compromete com uma agenda política e de pesquisa. A pesquisa acadêmica tem ratificado a importância e a legitimidade da escuta atenta e ética às crianças (Carvalho; Müller, 2010), o que é fundamental para a elaboração de políticas públicas integradas para a infância. Para que a participação das crianças seja considerada nas discussões políticas, deve-se conhecer o que elas necessitam através de uma escuta direta. A análise aqui apresentada mostra que a pesquisa pode operar na contracorrente do senso comum ao explorar conceitos que são próximos e familiares, como o de família e o de infância - mas que demandam uma complexa discussão.

\section{Família e Abrigo}

Família não é uma categoria nem natural nem universal dos grupos humanos, mas aparece como um componente estrutural e cultural das sociedades. James e James (2008) explicam que é intrínseca à concepção de família uma contradição

2. Para manter o anonimato dessas instituições, os abrigos serão identificados como Abrigo $A, B$ ou $C$. 
interna: ao mesmo tempo em que é conhecida por todos é também imprecisa, já que todas as famílias são diferentes.

Ao estudar os processos de circulação de crianças nos meios populares em Porto Alegre, Fonseca (2002) revelou dinâmicas familiares alternativas, que também são identificadas em outros setores sociais, como a consideração de mais de uma mãe, por exemplo. A autora aponta uma tendência em entender qualquer desvio ao modelo familiar nuclear como problemático. Neste sentido, Fonseca (1999) sugere que certas premissas do senso comum, que por vezes ganham legitimidade científica, devem ser revistas, dentre elas a idealização de um modelo nuclear de família em contraposição a outros, considerados patológicos.

Outros autores têm atentado para o preconceito evidente em algumas pesquisas, que apresentam um conceito conservador de família, sobretudo quando analisam os grupos populares. Mello (1995, p. 57) pontua que mesmo no campo acadêmico não raro se encontra a:

Desorganização familiar como a única responsável pelo fracasso escolar e adaptativo das crianças. Mais ainda, ela aparece também como fonte da violência, do abandono de crianças e da marginalidade dos jovens, ou seja, a família é responsável pelo que aparece como o fracasso moral dos seus membros.

O Plano Nacional de Promoção, Proteção e Defesa do Direito de Crianças e Adolescentes à Convivência Familiar e Comunitária (2006), com base no ECA, reconhece a família como o ambiente de excelência para o desenvolvimento da criança e do adolescente e é um subsídio para a reformulação de práticas de atendimento à família e à criança. Contudo, não raramente, a família de classes populares é concebida como desestruturada e imoral, o que afeta a relação entre Poder Judiciário, equipes do abrigo e famílias. Serrano (2008, p. 162) argumenta que as concepções construídas pelas equipes do abrigo sobre as famílias de origem interferem diretamente na política de manutenção do vínculo delas com as crianças. Essas concepções socialmente construídas não raramente responsabilizam os pobres pela sua própria situação de marginalização.

Também é importante reconhecer que a própria classe média brasileira não mais se encaixa no padrão nuclear e vem sofrendo um conjunto de reconfigurações (Porreca; Romanelli, 2004; Romanelli, 1991, 2003). Conceituar negativamente as dinâmicas familiares das camadas populares só atrapalha a compreensão de processos complexos. Além disso, um melhor entendimento destas dinâmicas apoiaria mais efetivamente crianças acolhidas nestas instituições e suas famílias, assim como viabilizaria políticas públicas em consonância com as necessidades desses grupos. Portanto, de acordo com Fonseca (1999), é necessário considerar 
a existência de dinâmicas alternativas, e não piores, ao invés de legitimar como único o modelo moderno de família conjugal.

Considerando que a institucionalização de crianças em abrigos está atrelada a uma ideia de controle da pobreza, é importante buscar na legislação subsídios para o entendimento de família e infância. Sem dúvidas, o ECA apresenta uma concepção vanguardista ao posicionar crianças e adolescentes como sujeitos de direitos, abandonando o paradigma anterior postulado pelo Código de Menores (1979), que era dirigido somente àqueles em "situação irregular". Segundo Basílio (2003), não se trata mais de uma política de proteção voltada à exceção - o menor infrator ou a família omissa - mas a todas as crianças e adolescentes. Assim, considerando todos como sujeitos de direito, o ECA, em seu art. 50, assegura que crianças e adolescentes não serão objeto de qualquer forma de negligência, discriminação, exploração, violência, crueldade e opressão. Passados dezenove anos, a lei no 12.010/2009 em seu art. $19, \S 2^{\circ}$, defende que a permanência de crianças e adolescentes em programa de acolhimento institucional não poderá ser prolongada por mais de dois anos, salvo em algumas exceções, desde que comprovada a necessidade.

No entanto, o que se observa é um distanciamento entre os objetivos legais e o que ocorre na prática com crianças e adolescentes abrigados. Primeiro porque para muitos deles o abrigo não é uma medida provisória, mas sim, uma experiência que se estende por um longo período de suas vidas, caracterizando “o provisório que se torna prolongado" (Oliveira, 2007, p. 41). Ainda que a normativa legal compreenda a necessidade de preservação da criança na família, não raramente, na prática, exclui-se qualquer outra dinâmica familiar que não se encaixe no modelo nuclear e/ou conjugal.

De acordo com James e James (2008, p. 57) os laços de parentesco nos quais a família está baseada, não importando se fortes ou fracos, continuam definindo os parâmetros de família. Assim, apresento a seguir a metodologia desenhada especialmente para captar o ponto de vista das crianças acerca deste processo de acolhimento institucional, ainda tão pouco explorado a partir do ponto de vista delas, o que igualmente já fora pontuado por Rossetti-Ferreira; Serrano; Almeida (2011, p. 23).

\section{Metodologia de pesquisa}

Craig (2003, p. 41) afirma que pesquisas têm cada vez mais envolvido crianças como participantes com voz e concepções sobre si e o mundo. Ademais alerta para a necessidade de que políticas não tragam prejuízo às crianças, mais 
precisamente, quando planejadores não têm noção sobre os efeitos negativos de suas intervenções sobre a vida delas. Craig ainda sugere que a literatura não aponta empecilho para o envolvimento das crianças, especialmente aquelas em situação de risco, nas decisões políticas.

Segundo James e James (2008), uma pesquisa focada nas crianças deve adotar métodos e procedimentos éticos que respeitem as crianças como participantes ao longo de todo o percurso. Este trabalho parte do pressuposto que crianças são competentes para expressar visões coerentes sobre um conjunto de temas sociais, incluindo questões muito sensíveis, como é o caso do acolhimento institucional. Geralmente, são dadas às crianças poucas oportunidades de escuta, o que não significa que não tenham o que dizer.

0 trabalho adota a estratégia de aproximação à criança sugerida por Montandon (1997). Esta autora argumenta que adultos possuem um sentimento paradoxal quando estudam a infância, considerando-a, ao mesmo tempo, estranha e familiar, objeto de rejeição ou idealização. No entanto, o pesquisador sensível a este fenômeno teria mais chances de enfrentá-lo do que aquele que o despreza e não se previne dos riscos. Assim, com vistas a capturar as perspectivas das crianças sobre a sua situação, mas também acerca de suas famílias, foi preciso estar atenta quando uma pergunta não foi compreendida ou mesmo procurar captar expressões peculiares empregadas por cada dupla de irmãos.

Importante na prática de pesquisa com crianças é superar dicotomias, que a própria relação entre adultos e crianças impõe, mas que deve ser des/re/construída. Experiências, ideias e sentimentos das crianças não podem ser entendidos como manifestações completamente independentes do mundo dos adultos e, neste caso, de duas instituições sociais as quais se relacionavam diretamente - família e abrigo. Montandon (1997, p. 20) igualmente argumenta que, a partir da comparação entre crianças e adultos, um conjunto de dicotomias é produzido durante a pesquisa - maturidade/imaturidade, racionalidade/irracionalidade, ser individual/ser social, o que precisa ser considerado - e também superado.

$\mathrm{Na}$ primeira etapa da pesquisa busquei identificar causas e motivos para o acolhimento institucional das crianças, assim como mapear experiências com as famílias de origem. Para isso, primeiramente lancei mão do Plano Individual de Atendimento (PIA) de cada criança. Em seu art. 101, $\S 4^{\circ}$, o ECA menciona que a entidade responsável pelo programa de acolhimento institucional ou familiar deverá elaborar um plano individual de atendimento logo após o acolhimento da criança.

Na sequência, inspirada no trabalho metodológico de Corsaro (1997), optei pela "entrada reativa" no campo: no abrigo, eu me aproximava das áreas de brinquedo e televisão, sentava e esperava as reações das crianças. Elas se aproximavam 
e, geralmente, sem muitos preâmbulos, me contavam sobre a sua história de acolhimento. Nesta etapa da pesquisa identifiquei que poucas crianças mantinham contato com sua família. Por este motivo, ao planejar a segunda fase de geração de dados, a pesquisa foi expandida para outros dois abrigos públicos da mesma cidade, incorporando uma dupla de irmãos de cada um deles.

A possibilidade de pesquisa com irmãos não havia sido considerada inicialmente, contudo, essa é uma situação decorrente da própria política do ECA, que em seu artigo 92, postula o não desmembramento do grupo de irmãos em situações de acolhimento institucional. Além disso, Almeida (2009, p. 159) chama atenção que pesquisas com irmãos acolhidos em instituições ainda não foram amplamente desenvolvidas e argumenta que se trata de uma relação que pode ser a mais duradoura durante a vida, especialmente por terem a possibilidade de compartilhar a infância, adolescência, fase adulta e velhice.

Punch (2002) expõe que pelo fato de a posição social das crianças ainda ser marginalizada e de crianças serem intrinsecamente diferentes, a pesquisa com elas tem uma natureza distinta daquela desenhada para adultos. Sendo assim, os métodos elaborados para este trabalho poderiam ser entendidos como não tradicionais (Corsaro, 2011), no sentido que incorporam formas de comunicação que se preocupam e se alinham às peculiaridades da infância.

Para a segunda etapa de geração de dados, construí uma combinação de métodos, tomando como inspiração alguns estudos com crianças desenvolvidos especialmente para situações de acolhimento institucional (Rossetti-Ferreira; Serrano; Almeida, 2011). Planejei três momentos, procurando dar às crianças a oportunidade de controlar o ritmo e a direção do assunto. Embora houvesse uma temática que orientava cada encontro, garanti que a participação das crianças ocorresse de forma espontânea. Os grupos de discussão I e II, que contaram com a participação das seis crianças juntas, foram pensados com o objetivo de lidar com o desequilíbrio de poder inerente à pesquisa entre adulto e criança, que ao invés de ser negado, precisa ser explorado e superado.

(1) Grupo de discussão I: esse encontro objetivou explorar os motivos do acolhimento institucional, mas também as experiências das crianças na família de origem. Diferentemente de uma entrevista de grupo formal, pensei em um instrumento que motivasse a discussão sobre abrigo e casa. Preparei uma seção de conto da história “A Casa Sonolenta" (Wood, 2002), que motivaria a discussão subsequente sobre a vida antes do acolhimento.

(2) Grupo de discussão II: três fases foram planejadas para abordar o tema: "Quem faz parte da sua família?" A primeira enfocou a história “As Famílias do Mundinho" (Bellinghausen, 2007), que apresenta as diferentes possibilidades de arranjos familiares. Na segunda fase seria motivada uma discussão, motivada 
pela história. Um recurso pedagógico, e não clínico neste caso, foi considerado na terceira fase: o uso de famílias terapêuticas (tanto um conjunto de família branca como de afrodescendente ${ }^{3}$ ), totalizando 16 bonecos, para auxiliar as crianças a mostrarem arranjos de suas famílias de origem. Após apresentarem o arranjo de sua família, cada criança pode falar sobre ele e tirar uma fotografia para registrálo.

(3) Entrevista com dupla de irmãos: com as fotografias impressas dos arranjos com as famílias terapêuticas, o objetivo do encontro com os irmãos era mostrar a eles esse material produzido e propor uma conversa informal. As fotografias foram mostradas, junto com as informações já disponibilizadas pela criança, contendo o nome das pessoas citadas. Ainda a cada criança foi dada a oportunidade de modificar seu arranjo, caso desejasse.

Craig (2003, p. 39) questiona se é possível trabalhar com crianças como atores independentes dos adultos que possuem responsabilidades legais sobre elas. 0 próprio autor responde que crianças não podem ser vistas como totalmente autônomas, uma vez que a infância não é um conceito fixo, mas uma construção adulta, cujos limites são culturalmente determinados.

Na próxima seção serão expostos os dados gerados na pesquisa.

3. De acordo com o levantamento do Ipea (2003), de 20 mil crianças abrigadas, $58,5 \%$ eram meninos, e, dentre eles, $63,6 \%$ eram afrodescendentes. Considerando que uma dupla de meninos era afrodescendente, outra parda e a dupla de meninas era branca, optei por dar às crianças mais possibilidades de escolha para a composição de suas famílias. Ainda assim, reconheço que os próprios limites do recurso pedagógico não representam a diversidade de raças e etnias encontradas no Brasil. 


\section{Resultados}

0 quadro a seguir sintetiza algumas informações sobre as crianças:

\section{Quadro 1: INFORMAÇÕES SOBRE PROCESSOS DE ACOLHIMENTO INSTITUCIONAL DAS CRIANÇAS}

\begin{tabular}{l|c|c|c|c|l|l}
\hline Nome & $\begin{array}{c}\text { Data de } \\
\text { nascimento }\end{array}$ & $\begin{array}{l}\text { Data do 10 } \\
\text { acolhimento } \\
\text { institucional }\end{array}$ & $\begin{array}{l}\text { Data do 20 } \\
\text { acolhimento } \\
\text { institucional }\end{array}$ & $\begin{array}{c}\text { Institui- } \\
\text { ça }\end{array}$ & $\begin{array}{l}\text { Motivo do } \\
\text { acolhimento } \\
\text { institucional }\end{array}$ & $\begin{array}{l}\text { Data da reinte- } \\
\text { gração familiar }\end{array}$ \\
\hline Beatriz $^{4}$ & $24 / 6 / 2002$ & $18 / 2 / 2010$ & $x$ & Abrigo A & Maus-tratos & $20 / 8 / 2010$ \\
\hline Carla & $10 / 4 / 1999$ & $18 / 2 / 2010$ & $x$ & Abrigo A & Maus-tratos & $20 / 8 / 2010$ \\
\hline Diego & $15 / 3 / 2002$ & $\begin{array}{c}2007- \\
2 / 9 / 2008\end{array}$ & $24 / 8 / 2009$ & $\begin{array}{l}10 \text { Abrigo A } \\
20 \text { Abrigo C }\end{array}$ & Maus-tratos & $x$ \\
\hline Fábio & $20 / 1 / 2000$ & $\begin{array}{c}2007- \\
2 / 9 / 2008\end{array}$ & $24 / 8 / 2009$ & $\begin{array}{l}10 \text { Abrigo A } \\
20 \text { Abrigo C }\end{array}$ & Maus-tratos & $x$ \\
\hline Gabriel & $16 / 9 / 2002$ & $15 / 3 / 2010$ & & $\begin{array}{l}10 \text { Abrigo A } \\
20 \text { Abrigo B }\end{array}$ & Negligência & $23 / 7 / 2010$ \\
\hline Heitor & $11 / 4 / 2005$ & $15 / 3 / 2010$ & & $\begin{array}{l}10 \text { Abrigo A } \\
20 \text { Abrigo B }\end{array}$ & Negligência & $23 / 7 / 2010$ \\
\hline
\end{tabular}

Fonte: PIA

Uma primeira organização dos dados combinados resultou na escrita de breves perfis das seis crianças, que aqui serão apresentados como três grupos de irmãos.

\section{Abrigo A - Beatriz e Carla}

Beatriz (7 anos) e Carla (10 anos) moravam com a mãe, a tia materna e o tio materno, na casa que pertenceu à avó materna, já falecida. No mesmo terreno,

4. Os nomes das crianças foram omitidos por exigência do Comitê de Ética e Vara da Infância e da Juventude do município onde se localizam os abrigos. Por esta razão, apresento nomes fictícios. 
residia em outra casa a segunda tia materna com seu companheiro e três filhas. Beatriz e Carla não são filhas do mesmo pai, por este motivo, a renda da família era composta por 250 reais da pensão alimentícia provida pelo pai de Carla, 100 reais da pensão alimentícia provida pelo pai de Beatriz, e 117 reais referentes ao beneficio do Programa Bolsa Família.

A família foi acompanhada pelo Conselho Tutelar desde 2005, sobretudo, devido aos problemas psiquiátricos diagnosticados em membros da família, como também a ingestão de bebidas alcoólicas pela mãe. Ainda que o Conselho Tutelar tenha encaminhado a mãe para serviços de saúde, ela não teria tomado providência. Em janeiro de 2010, a Unidade Básica de Saúde próxima à casa da família recebeu a denúncia de que a mãe teria agredido Carla fisicamente. As irmãs chegaram ao abrigo em fevereiro de 2010, com a convicção de que seriam reconduzidas à família na mesma semana. Por diversos meses, Beatriz não falava e se comunicava com a ajuda de Carla, que depois de uma rápida troca de olhares, entendia qual era o desejo da irmã.

A mãe, e somente ela da família, fazia visitas semanais às meninas. Sem dúvida trata-se de um vínculo presencial e emocional bastante forte e recíproco entre as três. Em alguns momentos, entretanto, a mãe compareceu atrasada e alcoolizada às visitas no abrigo. Neste estado, porém, a equipe não permitia a sua entrada, sobretudo porque as meninas demonstravam nervosismo.

Nem no primeiro nem no segundo encontro do grupo de discussão Beatriz falou uma palavra sequer, contudo, na entrevista, a menina me surpreendeu, ao querer falar sobre a sua família. No arranjo familiar, ela inclui membros da família que moravam no mesmo terreno antes de ela ser abrigada (mãe; irmã; tia materna, seu companheiro e três primas; um tio materno), mas exclui uma das tias maternas, precisamente aquela que morava na mesma casa. Ela inclui dois membros falecidos, a avó e o avô maternos, e um membro que nem morava na casa nem nunca a visitou no abrigo: seu pai. No entanto, mesmo no momento de conversa, ela não falou sobre ele. Carla apresenta exatamente o mesmo arranjo de membros do terreno onde morava antes de ser acolhida, mas exclui o seu pai.

As irmãs concordam que a mãe é uma pessoa legal, porém nervosa, que "gosta de fazer um barraco". Em defesa da mãe, em seguida, Beatriz diz que ela própria também gosta de "um barraco". Carla também lembra o quanto a mãe é chata, no entanto, resgatando algo positivo ligado a isso: "é porque ela é mãe coruja".

Ao encontrar Beatriz e Carla em agosto de 2010 fui informada por elas que passariam o próximo final de semana na casa da tia. Beatriz se mostrava mais animada que a irmã, que queria ficar no abrigo na companhia de uma amiga. $\mathrm{Na}$ próxima visita ao abrigo fui informada de que a tia havia obtido a guarda provisória das meninas por um ano e que ambas haviam sido desabrigadas. 


\section{Abrigo C - Diego e Fábio}

A família de Diego (8 anos) e Fábio (10 anos) é composta pela mãe, três irmãs (27, 19 e 18 anos) e quatro irmãos (25, 23, 21 e 12 anos). Em 2007 a mãe sofria de uso abusivo de álcool, o que acarretou no primeiro acolhimento dos irmãos, por motivo de maus-tratos. Naquela ocasião, ambos foram encaminhados ao abrigo, juntamente com um terceiro irmão. Em 2008, uma das irmãs obteve a guarda provisória de Diego e Fábio, porém, esta tentativa de reintegração familiar não teve sucesso. A própria irmã teria reconhecido não ter condições emocionais de cuidar dos irmãos, alegando já ter quatro filhos pequenos. Ela foi denunciada por vizinhos ao Conselho Tutelar por tê-los agredido. Logo, os dois foram encaminhados ao Abrigo C em 2009.

A mãe recebe uma pensão de 370 reais que lhe foi concedida após a morte do pai de uma das filhas. Em 2010 residia em uma cidade da região metropolitana de São Paulo, na casa de uma amiga, e confessa que vivia de forma itinerante. Contudo, mostrava-se empenhada para conseguir uma moradia na mesma cidade do abrigo, para poder recuperar a guarda dos filhos. Também afirma que está em abstinência do uso de álcool e que vinha se tratando em um Centro de Atenção Psicossocial (CAPS), o que foi interrompido devido às frequentes mudanças de domicílio. Por este motivo, a reintegração de Diego e Fábio ao convívio familiar é uma possibilidade a ser alcançada em médio prazo, visto que a mãe necessita de outros apoios para manter uma casa e garantir matrícula em escola de turno integral para as crianças.

Sobre a sua casa, antes do acolhimento, Diego a descreve como "tem piscina, tem três quartos", onde teria morado com a mãe e Fábio. Demonstrando constrangimento, Diego coloca a gola da camiseta na boca, ora a morde, ora esconde o rosto, e afirma que não quer voltar para casa, alegando que ninguém a "arrumou" (neste caso refere-se à casa da irmã que the agrediu). Diz que gosta do abrigo, dos "tios" e "tias" que o cuidam lá e dos amigos, mas que sente falta da mãe.

Tanto Diego como Fábio apresentam arranjos familiares que consideram alguns parentes vivos (sobretudo irmãos e sobrinhos), parentes falecidos (os avós), a mãe, quem mais aparece na fala deles e que os visita, e o pai lainda que jamais os tenha visitado).

Destaco duas questões interessantes no exercício de Diego, ao dispor a sua família. Ele solicitou massa de modelar para construir a sua mãe, afirmando que nenhuma das bonecas se parecia com ela. Também, depois de fotografar o arranjo, deitou-se no chão, ao lado dos bonecos, dizendo que naquele momento a família estava completa. Ainda que Fábio não apresente no seu arranjo, à irmã com quem 
morou até ser abrigado novamente, ele relembra que viveu em sua casa. Também menciona que somente a mãe o visita no abrigo.

\section{Abrigo B - Gabriel e Heitor}

Gabriel (8 anos) e Heitor (5 anos) e a irmã menor (3 anos) moravam com a mãe em um pequeno quarto alugado há poucos dias, em um bairro periférico de uma cidade da região metropolitana de São Paulo. A família contava com o rendimento de 120 reais do benefício do Programa Bolsa Família e deste valor despendia 100 reais com o aluguel. Até aquele momento, o pai jamais havia contribuído com pensão alimentícia e a mãe, desempregada, realizava trabalhos eventuais para prover os filhos.

Ao assumir um trabalho em um bar à noite, a mãe decidiu deixar os três filhos em casa, trancados. A vizinhança, ainda sem conhecer a família, não hesitou em chamar a polícia em uma noite de março de 2010, e denunciar que a mãe os deixava sozinhos, sem alimentos e companhia de um adulto. Nesta noite, as crianças foram encaminhadas ao Conselho Tutelar e, na manhã seguinte, para o abrigo.

Após o acolhimento institucional das crianças, a mãe obteve um emprego como auxiliar de limpeza em um clube, o que passou a the render o salário de 670 reais. Somado a isto, o pai passou a prover a pensão. A mãe então reformou uma pequena casa no mesmo terreno onde mora a família de seu irmão e sua mãe. $A$ equipe técnica do abrigo iniciou o processo de reintegração familiar das crianças, que consistiu em visitas ao novo domicílio e comprovação de renda da mãe.

Gabriel apresenta em seu arranjo familiar todos os membros da família que moravam com ele antes do acolhimento. Ainda que o pai pouco o visitasse, foi incluído no arranjo. Os avós, pais da mãe, também foram considerados. Durante a conversa com a dupla de irmãos, Gabriel substituiu os avós pelo tio materno e sua companheira, dizendo que eles eram legais e, assim, "gente normal”. Ele se deu conta então de que os avós não estavam dispostos no arranjo, mas mesmo assim, afirmou que faziam parte de sua família. Também lembrou dos primos e igualmente os incluiu. Ao falar sobre essas pessoas, Gabriel foca naquelas que moram com ele, a irmã e a mãe. Sobre a mãe, afirma que é "bastante legal, mas às vezes ela briga com a gente, quando a gente faz coisa errada". 0 pai é considerado "um pouco legal", mas "quando ele fica chato, ele fica muito chato". Gabriel menciona que o pai costumava ingerir bebida alcoólica em excesso.

Heitor manteve as pessoas do arranjo da fotografia e adicionou a madrinha, um amigo do Abrigo B e outra irmã, cujo nome não é o da sua. Ele explicou que seus avós maternos não moram juntos e é com a avó que ele mantinha mais contato 
antes do acolhimento. Heitor fala aleatoriamente das pessoas, não conseguindo descrevê-las na ordem do arranjo. Também, o amigo - ora chamado por um nome, ora chamado por outro - é mencionado por Heitor, que demonstra compaixão: "ele não tem cabelo e só tem roupa feia. É menor que a [irmã]". Em certo momento, ele afirma que sua família é composta por “[pela irmã menor] que mora comigo, e o meu irmão, e minha mãe, e minha tia e o [amigo do abrigo] e eu”.

\section{Discussão dos resultados}

Ainda que o ECA preconize a reintegração familiar, esforços de aproximação às famílias das crianças e tentativas de reintegração familiar só foram observados depois que os abrigos passaram a ser administrados por um novo grupo gestor, em 2010. Foi perceptível uma mudança de política do abrigo ao criar possibilidades para as famílias visitarem as crianças, ao ampliar os horários e oportunizar experiências próximas daquelas que poderiam ter em casa: para realizar refeições, assistir televisão, dar banho. Estas medidas, sem dúvida, auxiliaram a aproximação da família à criança.

Todavia, ainda é tensa, na prática, a relação entre as medidas de proteção e o conceito socialmente construído de família de classes populares. Isto porque o acolhimento de crianças ainda está relacionado à ideia de família desestruturada e omissa, sendo a negligência a maior justificativa para isso. Ao investigar com mais cuidado as trajetórias dessas crianças fica evidente que a negligência não é a causa, mas a consequência de problemas macrossociais decorrentes da pobreza e da falta de uma "rede de políticas públicas" (Oliveira, 2007) integradas de proteção à criança e à família. Neste sentido, o acolhimento institucional, ao invés de uma medida protetiva provisória, passa a ser uma solução à condição de pobreza das famílias. Ainda, segundo Oliveira (2007, p. 110), "esconde as razões estruturais da problemática social e acaba por responsabilizar as pessoas pela situação de miserabilidade em que se encontram".

Serrano (2008, p. 173) argumenta que, embora sejam identificadas situações de negligência no cuidado às crianças, estas não podem ser entendidas somente na esfera privada da família, mas nas próprias políticas públicas dirigidas à população desfavorecida. No caso da mãe de Gabriel e Heitor a situação de negligência é decorrente de um conjunto de carências e da falta de apoio para resolver questões que se acumulam: baixa renda, falta de emprego formal, falta de escola integral, falta de moradia apropriada.

Assim como negligência, maus-tratos às crianças decorrem de um sintoma associado à pobreza, qual seja o alcoolismo (Carício et al., 2011). As mães de Beatriz 
e Carla e de Diego e Fábio apresentavam quadro de uso abusivo e dependência de álcool e, em ambos os casos, obtiveram apoio de forma fragmentada, sem continuidade e conexão com outros equipamentos de atendimento.

Fica evidente que nenhuma das seis crianças estava devidamente informada e preparada para o ingresso no abrigo, sendo que os motivos, o tempo de permanência, o possível contato com os familiares, eram desconhecidos. Embora tendo como foco de investigação as interações de crianças no contexto escolar, Corsaro e Molinari (2005, p. 120) explicam que as dimensões temporais são importantes para as crianças anteciparem mudanças futuras e se prepararem para as transições nas suas vidas. No caso em questão, porém, as crianças não foram informadas sobre as decisões legais sobre seu futuro. No caso de Beatriz e Carla, o processo de reintegração familiar ocorreu de forma inesperada e sem um planejamento com a participação das crianças.

As crianças encontravam-se abrigadas com irmãos, o que influenciou a organização do grupo de três duplas para participar na pesquisa. Segundo Corsaro (1997), nos primeiros anos de vida muitas das rotinas entre crianças e adultos têm lugar na família e é por isso que as culturas de pares não surgem dos confrontos diretos das crianças no mundo adulto. São justamente os "eventos preparatórios" (Corsaro; Molinari, 2005) formais na família que habilitam as crianças para futuras interações com seus pares e outros adultos nos mais diferentes contextos sociais. Logo, ao considerar o abrigo como instituição de educação e cuidado extrafamiliar, mas que ao mesmo tempo preserva ora rotinas escolares, ora rotinas domiciliares, as crianças buscam nos irmãos os vínculos emocionais e segurança que primeiramente estabeleceram na família.

Ao considerar crianças e abrigo, seria impossível desconsiderar agência e estrutura como categorias de análise. James e James (2008) escrevem que, embora seja importante considerar a influência que a estrutura exerce sobre as crianças, elas também fazem escolhas e decisões como atores sociais autônomos. Isto porque, para os autores (2008), a vida social não consiste somente na reprodução das estruturas e instituições, mas é potencialmente transformadora, o que vai ao encontro do conceito de reprodução interpretativa de Corsaro $(1997,2011)$. E certamente as crianças exercem sua agência quando, dentro de um quadro novo e desconhecido que caracteriza o acolhimento, conseguem ressignificar relações, fortalecer a conexão com os irmãos, e manter os vínculos emocionais, ainda que não presenciais, com aqueles familiares que não veem por um longo período.

0 quadro a seguir sistematiza os arranjos apresentados pelas crianças em ordem de disposição dos familiares em uma superfície plana, da esquerda para a direita. 
Quadro 2: ARRANJOS FAMILIARES APRESENTADOS PELAS CRIANÇAS

\begin{tabular}{l|l|l|l|l|l}
\hline Beatriz & Carla & Diego & Fábio & Gabriel & Heitor \\
\hline Mãe & Mãe & Irmã & Sobrinha & Irmã & Avó \\
\hline Pai & Tia & Avó & Pai & H (masc) & Avô \\
\hline C (fem) & Tia & Sobrinho & Mãe & G (masc) & H (masc) \\
\hline B (fem) & Tio & Sobrinha & D (masc) & Pai & Amigo \\
\hline Prima & Tio & Avô & Avó & Mãe & Tia \\
\hline Prima & Prima & D (masc) & Avô & Avó & Irmã \\
\hline Prima & Prima & F (masc) & Irmão & Avô & Mãe \\
\hline Tia & C (fem) & Pai & Irmão & & G (masc) \\
\hline Tio & B (fem) & Sobrinha & $\mathrm{x}$ & $\mathrm{x}$ & $\mathrm{x}$ \\
\hline Avó & Prima & Irmã & $\mathrm{x}$ & $\mathrm{x}$ & $\mathrm{x}$ \\
\hline Avô & $\mathrm{x}$ & Mãe & $\mathrm{x}$ & $\mathrm{x}$ & $\mathrm{x}$ \\
\hline Tio & $\mathrm{x}$ & & $\mathrm{x}$ & $\mathrm{x}$ & $\mathrm{x}$ \\
\hline Total: 12 & Total: 10 & Total: 11 & Total: 8 & Total: 7 & Total: 8 \\
\hline
\end{tabular}

Fonte: material empírico

Fica evidente que as mães são a referência da família mais recorrente nas narrativas das crianças. Do ponto de vista macroestrutural, fazem parte das estatísticas brasileiras sobre o modelo de família monoparental feminino, que totaliza 15,1\% (IBGE, 2011). Do ponto de vista das relações, são as mães que visitam as crianças e buscam diferentes estratégias para viabilizar a reintegração familiar. No caso de Gabriel e Heitor, o tio materno e sua companheira cederam uma casa no seu terreno, onde já vivia a avó materna, para que a mãe dos meninos a reformasse. No caso de Beatriz e Carla, a tia materna casada obteve a guarda das meninas por um ano, o que facilitará o contato com a mãe, considerando que esta vive em uma casa no mesmo terreno. Parece que a mãe de Diego e Fábio não conta com qualquer apoio de membros da família, sendo que a própria caracteriza a sua moradia como "itinerante", o que apresenta já inicialmente um empecilho para a reintegração familiar dos meninos.

Não como uma presença física constante, mas como um vínculo emocional predominante, as crianças narram diferentes situações vividas com as mães, 
sobretudo, de quando ainda moravam com elas. Todas as crianças expressam o desejo de voltar para casa e viver com as mães, ainda que, especificamente no caso de Diego e Fábio, reconheçam que gostam do abrigo.

Os arranjos também evidenciam uma tendência de expansão da família para membros relacionados à linhagem materna. Considerando que a todas as crianças foram oferecidos 16 bonecos, o número mínimo utilizado foi 7, sendo o máximo 12. Somente Heitor agregou um membro, "amigo", ao seu arranjo, sendo que os demais incorporaram parentes vivos ou falecidos, eles próprios lcom a exceção de Fábio), o irmão também abrigado e a mãe.

A investigação empírica reforçou a noção de que "abrigamento é um marco na vida das crianças e crianças relatam sentimentos contraditórios" (Oliveira, 2007, p. 33). Em situações observadas no abrigo, não raramente os laços com outras crianças eram nomeados com referenciais familiares. Meninas mais velhas eram assim chamadas por "mãe" pelas crianças menores. Em relações de amizade, em alguns casos, as crianças se chamavam por "primos". 0 próprio Heitor chegou a chamar de primo um amigo do abrigo, por quem desenvolveu grande afeto. Estas estratégias utilizadas no abrigo, no entanto, não foram observadas nos arranjos familiares das crianças.

Sentimentos contraditórios podem ser explicados pela própria demanda de organização das relações que a situação de acolhimento institucional provoca. Em uma situação, Carla explicou que logo nas primeiras semanas desenvolveu uma forte relação de amizade com uma menina mais velha, que por estar no abrigo há mais tempo e saber se defender da "zoação dos grandes", garantia à ela e à irmã certa proteção.

0 conceito de resiliência também deve ser considerado para analisar a família na perspectiva das crianças. Uma criança resiliente enfrenta situações desfavoráveis e difíceis, mas mesmo assim, consegue adaptar-se a elas. 0 estudo de Alexandre e Vieira (2004) demonstrou que uma rede de apoio social possibilita condições de desenvolvimento adequado de crianças que vivem em situação de abrigo. Também mostrou a ênfase do contato físico e da busca constante de contato da presença do outro nos relacionamentos de irmãos, e que crianças demonstravam resiliência. Isto porque contavam com laços afetivos positivos com os irmãos mais velhos ou com a equipe do abrigo.

No presente trabalho, fica evidente que na dupla de irmãos os mais velhos assumem um papel de ligação entre os mais novos e a situação de acolhimento a eles imposta. Nos primeiros meses no abrigo, Carla traduzia para os adultos o que Beatriz necessitava, uma vez que não falava. Tanto entre as irmãs, quanto entre Gabriel e Heitor, havia uma cumplicidade explícita quando debochavam uns dos outros, e também, testavam poder na própria relação. Por vezes, ainda 
que menores e mais frágeis, os irmãos menores faziam questão de apontar as dificuldades dos mais velhos.

Por fim, também é importante destacar as estratégias que os irmãos menores encontraram para lidar com a dolorosa situação do acolhimento: Beatriz não falava e contava com a ajuda da irmã para se comunicar; Diego apresentou características da casa onde morava com a mãe que não coincide com os dados documentados; Heitor imaginou uma irmã perdida na floresta e incorporou o amigo do abrigo à sua composição familiar. Estes dados mostram que com a separação de suas famílias, são várias as alternativas encontradas pelas crianças para tolerar a nova conjuntura das suas vidas. Dentre elas, a identificação e o fortalecimento de pessoas de referência, sobretudo os irmãos, mas também, um subterfúgio absolutamente próprio da infância: a capacidade de transformar elementos da realidade em fantasia, onde tudo é possível, e tudo pode ser mudado.

\section{Conclusão}

Se por um lado o ECA apresentou conceitos bastante vanguardistas em relação à criança e ao jovem, posicionando-os como parte da sociedade e reconhecendo os seus direitos enquanto grupo que deve participar, ser protegido e provido, por outro, a ideia expressa de família ainda recai a um modelo conservador e com base em uma organização nuclear.

As famílias pobres não raramente são entendidas pelo sistema de proteção como nocivas às crianças. Obviamente, pobreza, alcoolismo, habitações precárias e agressão às crianças são inaceitáveis, contudo, as políticas sociais devem ir além da culpabilização das famílias e buscar as origens dos problemas. Sob o argumento de negligência, várias crianças são abrigadas, sem conhecerem os motivos precisos. A negligência é consequência última das precárias condições socioeconômicas, associada à falta de políticas públicas dirigidas a essa população específica. Também, ainda que os dados sejam escassos, há de se considerar que negligência também pode ser observada entre a classe média e alta, contudo, ganha outra conotação, tais como descuido, lapso, acidente.

Também é importante ressaltar que a reintegração familiar de duas duplas de crianças dependeu muito mais do apoio da família extensa do que da aplicação de uma política pública. A falta de apoio da sociedade como um todo e o surgimento de uma rede que mantenha a criança na família, certamente evitaria situações caracterizadas como negligência. Por exemplo, será que a mãe de Gabriel e Heitor teria evitado o acolhimento institucional de seus filhos, se tivesse contado com uma escola de qualidade de turno integral? Sem dúvida, as crianças emitiram 
várias pistas para pensar nestas questões de forma mais profunda.

A grande questão ainda incide sobre como escutar a criança para poder interferir em políticas públicas dirigidas a elas. Vários autores têm mostrado que a escuta é possível, mas para além disso Roberts (2003, p. 28) argumenta que o envolvimento de crianças nas políticas e práticas mostra que elas têm propostas interessantes para os desafios que enfrentam.

\section{Referências}

ALEXANDRE, Diuvani Tomazoni; VIEIRA, Mauro Luís. Relação de apego entre crianças institucionalizadas que vivem em situação de abrigo. Psicologia em Estudo, Maringá, v. 9, n. 2, p. 207-217. 2004.

ALMEIDA, Ivy Gonçalves. Rede social e relacionamento entre irmãos: a perspectiva da criança em acolhimento institucional. Dissertação (Mestrado)- Faculdade de Filosofia, Ciências e Letras de Ribeirão Preto, Universidade de São Paulo, Ribeirão Preto, 2009.

BAZÍLIO, Luiz Cavalieri. O Estatuto da Criança e do Adolescente está em risco? Os Conselhos Tutelares e as medidas socioeducativas. In: BAZILIO, Luiz Cavalieri; KRAMER, Sonia. Infância, Educação e Direitos Humanos. São Paulo: Editora Cortez, 2003. p. 29-50.

BELLINGHAUSEN, Ingrid Biesemeyer. As famílias do mundinho. São Paulo: DCL, 2007.

BRASIL. Código de Menores, Lei n. 6.697/79, 10 out. 1979.

. ECA - Estatuto da Criança e do Adolescente, Lei n. 8.069/90, 13 jul. 1990.

- Plano Nacional de Promoção, Proteção e Defesa do Direito de Crianças e Adolescentes à Convivência Familiar e Comunitária. Brasília, 2006.

. Lei n. 12.010, 3 ago. 2009.

CARÍCIO, Márcia Rique et al. Estratégia Saúde da Família: proporcionando suporte familiar e social frente ao alcoolismo. Saúde em Debate, Rio de Janeiro, v. 35, n. 88, p. 96-104, 2011.

CARVALHO, Alexandre Filordi; MÜLLER, Fernanda. Ética nas pesquisas com crianças: uma problematização necessária. In: MÜLLER, Fernanda (Org.). Infância em Perspectiva. São Paulo: Editora Cortez, 2010. p. 65-84.

CORSARO, William Arnold. The sociology of childhood. California: Pine Forge Press, 1997.

Sociologia da infância. Porto Alegre: Editora Artmed, 2011.

CORSARO, William Arnold; MOLINARI, Luisa. I Compagni: understanding children's transition from preschool to elementary school. New York: Teacher College Press, 
2005.

COSTA, Nina Rosa do Amaral; ROSSETTI-FERREIRA, Maria Clotilde. Famílias acolhedoras: uma análise de experiências no Estado de São Paulo. In: XII ENCONTRO CIENTÍFICO DO CINDEDI. Resumos. Ribeirão Preto, 2007.

CRAIG, Gary. Children's participation through community development: assessing the lessons from international experience. In: HALLETT, Christine; PROUT, Alan (Eds.). Hearing the voices of children: social policy for a new century. London: RoutledgeFalmer, 2003. p. 38-56.

DELGADO, Ana Cristina Coll; MÜLLER, Fernanda. Em busca de metodologias investigativas com as crianças e suas culturas. Cadernos de Pesquisa, v. 35, n. 125 , maio/ago. 2005.

FONSECA, Claudia Lee W. Quando cada caso não é um caso: pesquisa etnográfica e educação. Revista Brasileira de Educação, Rio de Janeiro, s/v, n. 10, p. 58-78, 1999. Mãe é uma só? Reflexões em torno de alguns casos brasileiros. Psicologia USP, São Paulo, v. 13, n. 2, p. 49-68, 2002.

GARZELLA, Mariana. 0 abrigo sob a perspectiva da criança. Monografia de Conclusão (Bacharelado em Psicologia)- Faculdade de Filosofia, Ciências e Letras de Ribeirão Preto, Universidade de São Paulo, Ribeirão Preto, 2008.

IBGE. Indicadores Sociais Municipais 2010: incidência de pobreza é maior nos municípios de porte médio. Disponível em: <http://saladeimprensa.ibge.gov.br/no ticias?view=noticia\&id=1\&busca=1\&idnoticia=2019>. Acesso em: 26 nov. 2013.

IPEA - Instituto de Pesquisa Econômica Aplicada. Levantamento Nacional dos Abrigos para Crianças e Adolescentes da Rede de Serviço de Ação Continuada (SAC). Brasília, 2003.

JAMES, Allison; JAMES, Adrian. Key concepts in childhood studies. London: Sage, 2008.

MELLO, Sylvia Leser. Família: perspectiva teórica e observação factual. In: CARVALHO, Maria do Carmo Brant (Org.). A família contemporânea em debate. São Paulo: Cortez, 1995.

MONTANDON, Cléopâtre. L'éducation du point de vue des enfants: un peu blessés au fond du cœur. Paris: Editions L'Harmattan, 1997.

OLIVEIRA, Rita de Cássia S. Quero voltar para casa: o trabalho em rede e a garantia à convivência familiar e comunitária para crianças e adolescentes que vivem em abrigo. São Paulo: AASPJ-SP, 2007.

PORRECA, Wladimir; ROMANELLI, Geraldo. Separação conjugal e segunda união de casais católicos. Serviço Social e Realidade (Unesp/Franca), v. 13, n. 1, p. 71-87, 2004.

PUNCH, Sam. Research with children: the same or different from research with adults? Childhood, v. 9, n. 3, p. 321-341, Aug. 2002. 
ROBERTS, Helen. Children's participation in policy matters. In: HALLETT, Christine; PROUT, Alan (Eds.). Hearing the voices of children: social policy for a new century. London: RoutledgeFalmer, 2003. p. 26-37.

ROMANELLI, Geraldo. Mudança e transição em famílias de camadas médias. Travessia, São Paulo, n. 9, p. 32-34, 1991.

- Paternidade em famílias de camadas médias. Estudos e Pesquisas em Psicologia, Rio de Janeiro, v. 2, 79-95. 2003.

ROSSETTI-FERREIRA, Maria Clotilde; SERRANO, Solange Aparecida; ALMEIDA, Ivy Gonçalves (Orgs.). 0 acolhimento institucional na perspectiva da criança. São Paulo: Hucitec Editora, 2011.

Apresentação. In:

(Orgs.). 0 acolhimento institucional na perspectiva da criança. São Paulo: Hucitec Editora, 2011. p. 21-27.

SERRANO, Solange Aparecida. 0 abrigamento de crianças de 0-6 anos de idade em Ribeirão Preto: Caracterizando esse contexto. Tese (Doutorado)- Faculdade de Filosofia, Ciências e Letras de Ribeirão Preto, Universidade de São Paulo, Ribeirão Preto, 2008.

SOLON, Lilian de Almeida Guimarães. A perspectiva da criança sobre seu processo de adoção. Dissertação (Mestrado)- Faculdade de Filosofia, Ciências e Letras de Ribeirão Preto, Universidade de São Paulo, Ribeirão Preto, 2006.

WOOD, Audrey. A casa sonolenta. São Paulo: Editora Ática, 2002.

Recebido em julho de 2013

Aprovado em novembro de 2013

Fernanda Müller é doutora em Educação pela Universidade Federal do Rio Grande do Sul e professora da Faculdade de Educação da Universidade de Brasília. Email: fernandamullerdunb.br 